\title{
HEMIPARESIA ESQUERDA CONSECUTIVA A EMPEÇONHAMENTO POR BOTHROPS JARARACUSSU
}

\author{
N.APOLEAO L. TEIXEIRA *
}

Que o empeçonhamento ofídico pode dar lugar a hemiplegias orgânicas, testemunham diversos trabalhos, a que mais adiante nos reportaremos. A hemiplegia cerebral infantil - ou, como Gareiso e Escardó ${ }^{1}$ acham mais correto denominar, hemiplegia espasmódica infantil - seria a mais freqüente, casos havendo, entretanto, em que só se observam mo. noplegias ou, como no que apresentaremos, hemiparesias, acompanhadas ou não de movimentos involuntários (atetose, córeo-atetose, etc.), distúrbios sensitivos e perturbações psíquicas.

A hemiplegia é o que mais habitualmente ocorre. Tem uma caraterística particular, qual seja a de acarretar verdadeira parada no desenvolvimento da musculatura de todo o domínio corporal afetado. Os ossos dela participam, mostrando-se diminuídos em espessura e comprimento. Observa-se verdadeira assimetria osteomuscular, igualmente comprovada no tórax e abdome. Lembra Déjerine ${ }^{2}$ que a parada de desenvolvimento é tanto mais marcada quanto mais cedo fôr atingida a criança. Se isso ocorrer após a segunda infância (hemiplegia dos adolescentes), é, naturalmente, menos acentuada. A atrofia predomina no niembro superior, sendo uniformemente disposta em todos os grupos musculares. Poder-se-á observar em todos os graus possíveis, desde sua quase ausência até um desenvolvimento extremamente acentuado. No membro inferior é, em geral, menor. Normalmente, atinge os músculos do tronco, contribuindo para a assimetria torácica e abdominal que se observa. De par com os fenômenos tróficos, assinalados nas linhas precedentes, verifica-se atrofia do testículo e da mama do mesmo lado.

A paralisia facial - geralmente antes paresia que paralisia - predomina nos domínios do facial inferior. Às vezes, é preciso procurá-la com cuidado, durante os movimentos da mímica sobretudo, podendo-se então constatar diferença de motilidade entre as duas metades da face. A face é, em geral, assimétrica, o mesmo podendo ocorrer com a corres-

* Do Corpo de Saúde do Exército. Assistente da cadeira de Clínica Psiquiátrica da Faculdade de Medicina da Universidade do Paraná.

1. Gareiso, A. e Escardó, F. - Manual de Neurologia Infantil. Ed. El Ateneo, Buenos Aires, 1942, Págs. 230-32.

2. Déjerine, J. - Sémiologie du système nerveux. Masson Cie, Paris. 
pondente metade do crânio, que então se mostra achatada, ou, mais raramente, deprimida. A atrofia, agindo sôbre músculos e ossos, acentua a assimetria. Paralelamente, observam-se atrofia do ôlho, da orelha e da metade da língua.

A atitude dos enfermos é típica: antebraço fletido sôbre o braço, mão sôbre o punho; o polegar, em adução, recoberto pelos demais dedos flexionados sôbre a palma. $\mathrm{O}$ membro inferior, em extensão, mostra o pé em eqüino-varo mais ou menos pronunciado. Há sempre escoliose, de concavidade voltada para o lado comprometido. Distúrbios vasomotores aparecem sempre. Traduzem-se por cianose, hipotermia, dificuldade em desaparecer o sinal da pressão exercida sôbre o dorso da mão, etc.

Geralmente, observa-se maior ou menor grau de espasticidade ou hipertonia muscular, somada a hiperreflexia tendinosa, hiporrefletividade cutânea, clono do pé e da rótula, sinal de Babinski acompanhado ou não dos seus sucedâneos (reflexo de Gordon, Strümpell, Schäffer, etc). Em alguns casos, entretanto, pode o exame do tono muscular revclar certo grau de hipotonia nos dedos da mão, permitindo, p. ex., colocar em hiperextensão as falanges, falanginhas e falangetas, ou chegar a cobrir a região do ombro com a palma da mão. Demonstraria isso não estar a lesão inteiramente localizada na zona córtico-piranidal, havendo simultâneo comprometimento dos centros tonígenos cerebrais (Gareiso-Escardó). "Em certos casos", escrevia Pierre Marie, já em 1886, "o caráter desta paralisia está longe de ser espástico". Donde a divisão feita por êste autor: tipo A (tipo estriado de Babinski) - acompanhado de atetose ou córeo-atetose, sem atrofia e sem contraturas pronunciadas, isto é, sem lesão do feixe piramidal; tipo B - com evidente contratura, alterações tróficas dos membros e conseqüente deformação dos mesmos, com toda a conhecida sintomatologia das lesões do feixe piramidal. Devem êstes tipos clássicos ser apenas tidos à conta de modelos; nosogràficamente, existem outros, intermediários, mais comumente encontrados.

E freqüente, na hemiplegia cerebral infantil, a existência de crises epileptiformes ou de ausências. Aquelas são, habitualmente, unilaterais, começando pelo lado paralisado. Podem existir, para o lado do membro superior principalmente, movimentos involuntários - coréia, atetose, movimentos córeo-atetóticos — o que implica em comprometimento do sistema extrapiramidal. Tais movimentos são tão comuns na hemiplegia infantil, quão raros na dos adultos. Alterações sensitivas são excepcionais e, quando existem, são sumamente leves, radicando-se na periferia dos membros. Aloysio de Castro ${ }^{3}$ escreve que a astereognosia pode ser observada, vez por outra. Explica-a, recordando que o sentido estereognóstico é fruto de especial educação, aperfeiçoada vida em fora; ora, insta-

3. Castro, A. - Tratado de semiótica nervosa. Ed. Briguiet, Rio de Janeiro. 
lando-se a hemiplegia em tenra idade, impede se desenvolva o referido sentido.

Pode haver comprometimento psíquico, traduzido em déficit intelectual mais ou menos marcado. Diga-se de passagem não ser êle proporcional à intensidade da hemiplegia: é bem menor quando, por exemplo, está em jôgo uma lesão capsular, e muito mais acentuado quando se trata de lesão cortical extensa ou de porencefalia. Casos há em que a inteligência não é atingida ou é pouco tocada. Neste caso, o indivíduo aprende bem o que se lhe ensina e tem boa memória. Em troca, há comprometimento volitivo e afetivo, com distúrbios do pragmatismo, debilitação do senso moral e perversão do caráter. De modo geral, pode observar-se a oligofrenia, sob qualquer das suas fórmas - debilidade mental, imbecilidade ou idiotia. No estudo que faz da debilidade mental, acentua Henrique Roxo ${ }^{4}$ ser ela freqüente em conseqüência à diplegia ou hemiplegia cerebral infantil, fazendo-se então acompanhar, ao dizer de Laignel-Lavastine, da "síndrome de debilidade motora de Dupré, caraterizada por sincinesia, sinal de Babinski, exagêro de reflexos, desazo de movimentos e paratonia ou impossibilidade de fazer o braço mole". $\mathrm{Na}$ maioria dos casos, as perturbações da inteligência que acompanham as hemiplegias infantis permanecem estacionárias, raramente apresentando o caráter de uma demência progressiva (Bourneville).

São em grande número as causas da hemiplegia cerebral infantil. Costuma esta ocorrer : 1 - Na vida intra-uterina, consecutiva a arterite infecciosa, parada de desentvolvimento, heredolues ou lesões sof ridas pelo feto. Alô Guimarães atribui importante papel a estas causas pré-natais, responsáveis que são por grande número de agenesias e disgenesias cerebrais e seu longo cortejo de conseqüências ; 2 - Por ocasião do nascimento, devido a hemorragia meníngea, nos partos laboriosos; 3 - Após o nascimento; a) por traumatismo direto, nas fraturas cranianas com afundamento, nas feridas penetrantes do crânio por bala ou estilhaço de obus; b) por traumatismo indireto, repercussão à distância dos traumatismos cranianos; a) nos empeçonhamentos ofídico e escorpiônico; d) nas intoxicações alcoólica, arsenical, mercurial, etc; e) nas doenças infecciosas. "Tôdas as infecções são suscetíveis de se complicarem de hemiplegia" (Déjerine). A causa determinante seria sempre uma encefalite supurada, uma meningite, um processo arterítico ou um êmbolo partido do coração. Foi observado no difteria (Seifert), escarlatina (Rolleston), pneumonia (Bellot), febre tifóide (Osler), coqueluche (Neurath), sarampo, meningites agudas e tuberculosas, etc; f) no decurso dos seguintes estados mórbidos: diabetes, uremia, terçã maligna, icterícias graves e no pleuris com derrame, antes ou após toracocentese (Levy-Valensi).

4. Roxo, H. - Manual de Psiquiatria. Ed. Francisco Alves, Rio de Janeiro. 
Qual a patogenia das hemiplegias infantis no empeçonhamento ofidico? O doente que estudaremos, de acôrdo com nosso ponto de vista e com sua história clínica, deve a hemiplegia que apresenta a envenenamento ofídico, tendo sido fator responsável a peçonha do Bothrops jararacussu. No maior das vezes, quadros como o que dentro em pouco descreveremos, são devidos a empeçonhamento crotálico, dado o grande neurotropismo do veneno do Crotalus terrificus. Por empeçonhamento botrópico, há apenas, ao que sabemos, um registro anterior a êste, registro também feito por nós em $1943^{5}$. O ofidio causador, foi, neste caso, Bothrops jararaca.

Assinalemos, de passagem, que Eduardo Vaz e Anibal Pereira ${ }^{6} \mathrm{em}$ excelente estudo, descreveram o seguinte: "No estudo experimental do veneno botrópico, segundo a espécie de serpente, ora a ação proteolítica é mais acentuada (B. neuwiedii), ora a hemocoagulante mais destacada (B. atrox), ou intermediária entre Crotalus e Bothrops (B. jararacussu). O grifo é nosso. Poderá isso explicar a hemiplegia em nosso caso atuai? Acreditamos que sim. Para Calmette ${ }^{7}$, o veneno ofídico deveria sua toxidez a dois princípios: neurotoxina, neurotrópica, e hemorragina, hemolítico e endoteliotóxico. No veneno dos Colubrídios, predomina o primeiro; no dos Viperídios, prevaleceria o segundo.

No primeiro trabalho que sôbre o assunto publicamos, procuramos explicar o mecanismo da hemiplegia, atribuindo-a a hemorragiạs provocadas pela ação da hemorragina sôbre o endotélio vascular. Estava isso de acôrdo com as conhecidas experiências de Vital Brazil ${ }^{8}$, levadas a efeito em sagüis, cães e Macacus rhesus, com a injeção de veneno de diversas cobras. Em todos, o achado necróptico era o mesmo: hemorragias arteriais poliviscerais, particularmente cerebrais, sendo freqüentes os hematomas subpiais. Para Octavio da Silveira, aqui, a exemplo do que ocorre em outras hemiplegias, o espasmo vascular seria o fator responsável mais comum. Para Eduardo Vaz e Anibal Pereira, já citados, ocorreria a hemiplegia, "em conseqüência da coagulação intravascular e do embaraço mecânico da circulação". Lembra Déjerine que, "à autópsia, as lesões constatadas são as mesmas que as da hemiplegia do adulto, a saber, focos centrais de hemorragia ou de amolecimento, lesões cortiticais de amolecimento - placas amarelas - consecutivas a uma trombose por endarterite, ou a embolia". Tôdas estas diferentes maneiras de

5. Teixeira, N. L. - Hemiplegia cerebral infantil por empeçonhamento botrópico. Rev. Med. Mil., 3, 1943.

6. Vaz, E. e Pereira, A. - Hemocoagulação pelo veneno botrópico. Bol. Sanat. S. Lucas (S. Paulo) junho, 1940.

7. Calmette, A. - Les venins, les animaux venimeux et la sérotherapie antivenimeuse. Em vol. XXII, Coleção Sergent, Paris, págs. 76-78.

8. Vital Brazil - Contribuição ao estudo do ofidismo. Bio!. Méd. (Rio c'e Janeiro), $27: 3,1938$. 
encarar o assunto não impedem se estabeleça estreita filiação entre o empeçonhamento ofídico e as perturbações motoras logo a seguir observadas.

Duas observações de hemiplegia infantil por envenenamento ofídico foram feitas anteriormente por Octavio de Magalhães ${ }^{9}$, ambas de hemiplegia orgânica. Ignoramos qual o ofídio responsável, no primeiro caso ; no segundo, foi a cascavel. O mesmo autor, em colobaração com Guimarães ${ }^{10}$, publicou ainda interessante caso da mesma natureza, consecutivo êste, à picada de escorpião.

Passemos agorà à nossa observação (n. ${ }^{\circ} 65$ de nosso arquivo) :

M. G. S. (fig. 1), brasileiro, branco, solteiro, 22 anos, lavrador, internado para verificação de sua aptidão para o serviço militar.

Queixa do doente: "esquecimento" do braço esquerdo e ataques (sic).

Antecedentes familiais sem importância para o caso. Antecedentes pessoais: Nascido a têrmo, de parto normal. Andou e falou na época normal. Coqueluche aos 4 anos, sem complicações. Varicela e sarampo, aos 21 anos. Nega moléstias venéreas. Não freqüentou escolas. Nunca procurou mulheres. $\mathbf{E}$ tabagista moderado. Não é etilista.

Histórico: Até os 18 anos, foi rapaz vivo e sadio. Com esta idade, foi, ao colher milho, picado, à altura do têrço médio da perna esquerda, por cobra venenosa, morta e identificada como jararacussu. No momento da picada, sentiu forte dor local e "amarelidão" na vista. Ao mesmo tempo que o ferimento sangrava bastante, instalou-se rápido e progressivo edema que tomou tôda a perna. Manifestaram-se, logo a seguir, hemorragias gengivais. Conduzido à casa, sentiu-se bruscamente perder os sentidos. Permaneceu em absoluto estado de inconsciência durante 10 dias. Durante outros 50 dias guardou o leito com hemiplegia esquerda. Ao fim dêstes, levantou-se: andava com grande dificuldade e sua fala era engrolada e incompreensível. A pouco e pouco, recuperou o uso da palavra; a volta de movimentos nos membros superior e inferior só a pouco foi conseguida, com o passar dos anos, e mesmo assim de maneira deficiente. Seu psiquismo sofreu bastante; de esperto e atilado que era, passou a sentir-se entorpecido, difícil de compreensão e tardo de idéias. 15 dias depois de haver-se levantado, passou a apresentar crises epileptiformes típicas, que passaram a se repetir com freqüência, perdurando até a presente data (mau grado ter permanecido por mais de um mês em nosso serviço não pudemos assistir a nenhuma delas).

Exame clinico: Leucodermo. Suas çaraterísticas morfológicas permitem-nos incluí-lo no tipo astênico-displástico do esquema de Kretschmer. Hiponutrido. Assimetria facial. Hipotrofia muscular de todo o dimídio corporal esquerdo, da coxa principalmente. Mensurações: Antebraço (1/3 médio) - Direito: $19 \mathrm{cms}$; Esquerdo: $16 \mathrm{cms}$. Braço (1/3 médio) - Direito: $24 \mathrm{cms}$; Esquerdo: $22 \mathrm{cms}$. Perna (1/3 médio) - Direita : $36 \mathrm{cms}$.; esquerda : $32 \mathrm{cms}$. Coxa (1/3 médio) Direita : $40 \mathrm{cms}$.; esquerda: $36 \mathrm{cms}$. Pêlos finos e escassos. Distribuição feminina dos pêlos pubianos. Exame dos aparêlhos: Sem distúrbios dignos de nota.

9. Magalhães, O. - Hemiplegia orgânica provocada pelo veneno ofídico. Ciência Méd., 3; 302-307, 1925.

Magalhães, O. - Hemiplegias orgânicas provocadas pelos venenos ofídico e escorpiônico. Rev. Med. Cir. Brasil, $43: 113-118$, pags. 113-118.

10. Magalhães, O. e Guimarães, R. - Algumas observações sôbre picadas de escorpiões, Brasil Méd., 27:461 (5, julho) 1941. 
Exame neurológico: Orientação e estática: normais. Ausência do sinal de Romberg. Motilidade ativa voluntária: Paresia facial esquerda, predominando no domínio do facial inferior, revelada pelo apagamento dos sulcos nasogeniano e nasolabial do mesmo lado, repuxamento da comissura labial direita e acentuada pelos movimentos da mímica. Fenda palpebral esquerda mais fechada do que a direita. Paresia do membro superior esquerdo, com leve grau de hipotrofia muscular. Polegar esquerdo em adução. Movimentos de flexão e extensão possíveis no braço, antebraço, mão e quirodáctilos, exceção feita do polegar, que não os executa.

Fôrça dinamométrica - Mão direita: 32; Mão esquerda: 10. Discreta hipotrofia muscular do tronco, o que acarreta assimetria torácica e abdominal. Membro inferior paresiado, apresentando hipotrofia, mais acentuada na coxa. O pé, em extensão, esboça a posição eqüino-varo. Marcha hemiparética, discreta.

Motilidade ativa involuntária: Ausência de tiques, tremores, coréia, atetose e movimentos córeo-atetóticos. Motilidade passiza: A hipertonia muscular observada não impede sejam possíveis movimentos passivos dos membros superior e inferior, que se fazem sem dor. Refletividade: Superficial: reflexos plantares normais; ausência do sinal de Babinski; reflexo cremastérico esquerdo, tórpido; os demais reflexos superficiais, normais. Profunda: hiperreflexia tendinosa; não há clono da rótula e do pé. Especial: isocoria; reflexo pupilar à luz (consensual e direto) normal; ausência do sinal de Argyll-Robertson. Sensibilidade: Hiperestesia táctil, térmica e dolorosa em todo o membro inferior esquerdo e face dorsal do antebraço do mesmo lado. Não há perturbação das sensibilidades subjetiva e especial. Trofismo: Pêlos finos e quebradiços. Pele fina, fria e violácea. Atrofia da orelha, mama e ôlho esquerdo. Hipotrofia muscular, já assinalada nas linhas precedentes.

Exame psíquico: Apresenta acentuado déficit intelectual. Sua atenção espontânea é deficiente e a provocada sofrível; sua percepção é tarda, seu raciocínio moroso, sua imaginaçã̃o pobre. Idade mental: 11 anos. Não apresenta distúrbios sensoperceptivos ou da ideação. Memória, razoável. Orientado no meio, lugar e tempo. Anquilose pragmática. Razoável comportamento social e familial. Linguagem falada, escrita e mímica, normais.

Exame complementares: Sangue: Reações sorológicas da sífilis (Kahn e Kline), negativas. Líquor: Exame citológico, reações da albumina, reações coloidais e reações para a sífilis - nada revelaram de anormal.

O quadro sintomatológico acima descrito é, sem dúvida alguma, devido ao empeçonhamento botrópico. Tivesse êste ocorrido em mais baixa idade, e não aos 18 anos como aconteceu, e teríamos, não hemiparesia, mas hemiplegia como no caso que, anteriormente, publicamos (figura 2). Assinalemos, de passagem, que casos há em que se não observam todos os sintomas, normalmente existentes em casos dessa natureza. Bastará, então, fazer o paciente caminhar, usar seus membros, rir, falar, etc. para que se exteriorizem, embora de maneira não ostensiva. Podem ser observadas, nas hemiplegias cerebrais infantis, tôdas as gamas do processo encefalopático - desde o puramente motor até o associado com manifestações convulsivas e psíquicas. $O$ caso que ora apresentamos deve ser considerado o quarto até hoje registrado na literatura médica nacional, tendo os anteriores de hemiplegia cerebral infantil por empeçonhamento ofídico sido assinalados por Octavio de Magalhães (2 observações) e por nós mesmo (1 observação). 


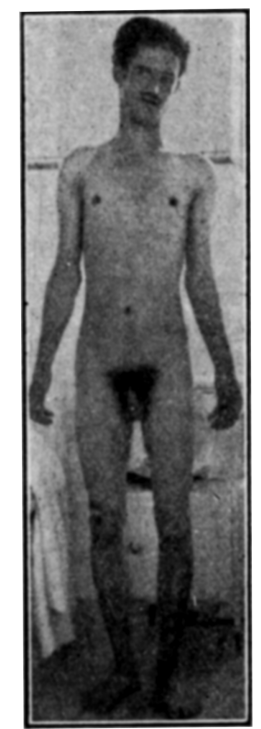

FIG. 1.- Hemiparesia esquerda por empeçonhamento botrópico (Bothrops jararacussu), ocorrido aos 18 anos de idade.

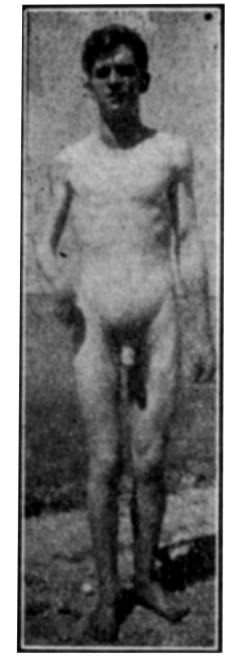

FIG. 2 - Hemiplegia cerebral infantil por empeçonhamento botrópico (Bothrops jararaca), ocorrido aos 11 anos de idade.

\section{RESUMO}

O A. apresenta uma observação de hemiparesia esquerda, consecutiva a envenenamento por Bothrops Jararacussu. E o segundo caso que publica, com idêntica etiologia; além das suas, há duas outras observações semelhantes, de Octavio de Magalhães.

Depois de discorrer sôbre as hemiplegias cerebrais infantís - mais comuns - lembra que estas nem sempre se acompanham de espasticidade, podendo apresentar-se, raramente, com hipotonia muscular, ou mesmo de coréia, atetose, ou movimentos córeo-atetóticos que falam em favor de comprometimento extrapiramidal.

Assinala, também, que crises epileptiformes - generalizadas ou parciais - podem ocorrer, o mesmo se podendo dizer de distúrbios psiquicos. Traduzir-se-iam, êstes, por déficit intelectual marcado, podendo ir desđe a debilidade mental até a idiotia; ou então, mesmo quando não há aparente comprometimento da esfera intelectual, por perturbações da afetividade, da vontade e do pragmatismo.

Passando em revista as causas mais freqüentes das hemiplegias cerebrais infantís, abre lugar, dentre elas, para os empeçonhamentos ofídico e escorpiônico (Magalhães e Guimarães). 
Estuda, a seguir, a patogenia das hemiplegias no decurso dos referidos empeçonhamentos, alinhando as hipóteses correntes, da preferência de conceituadas autoridades no assunto.

Transcreve, finalmente, sua observação clínica, da qual se pode concluir, sem dúvida possível, haver, no caso 'que apresenta, estreita e imediata ligação entre o envenenamento ofídico e a hemiparesia em estudo. O observado seria portador, além do mais, de crises epileptiformes generalizadas, aparecidas logo a seguir ao empeçonhamento.

Além da fotografia do caso que apresenta, mostra-nos o A. outra, de caso anteriormente publicado, êste, porém, de hemiplegia cerebral infantil típica, instalada aos 11 anos, após picada de Bothrops jararaca.

\section{SUMMARY}

The A. presents one observation of left side hemiparesis following poisoning by Bothrops Jararacussu. This is the second case reported by the $A$. both having identical etiology. There are two more similar observation's by Octavio de Magalhães.

After discussing the infantile cerebral hemiplegia, the A. calls attention to the fact that those hemiplegias do not always present spasticity, sometimes presenting muscular hipotony or even chorea, athetosis or choreo-athetotic movements, which suggest an extrapyramidal involvement The A. then stresses the fact that epileptiform crisis - either generalized or partial - may occur, as well as psychic disturbances. Those disturbances consist either of marked intellectual deficit which can go as far as idiocy, or else of disturbances of afectivity, will and pragmatism, even when no intellectual deficit can be detected.

Making a review of the most frequent causes of infantile cerebral hemiplegia the A. places among them the ophidic and scorpionic poisoning (Magalhães and Guimarães). Then the $\mathrm{A}$. proceeds studying the pathogen'y of the hemiplegia occurring in the course of those poisonings, referring to the current hipothesis, specially to those which are due to well known authorities on the subject.

The A. finally, includes the clinical observation of one case from which we can, no doubt, draw the conclusion that there is a close and immediate relationship between the ophidic poisoning and the hemiparesis reported, the patient presenting in addition generalized epileptiform crisis which have appeared immediately after the poisoning.

Not only the photograph of the case reported is included but also another of an already published case of typical cerebral hemiplegia following Bothrops Jararaca poisoning, studied in a child aged eleven.

$$
\text { Rua Coronel Dulcidio, } 956 \text {-. Curitiba (Paraná). }
$$

